\title{
Employee's Personality Traits, Work Motivation and Innovative Behavior in Marine Tourism Industry
}

\author{
Su-Chang Chen ${ }^{1}$, Ming-Chung $\mathrm{Wu}^{2}$, Chun-Hung $\mathrm{Chen}^{{ }^{*}}$ \\ ${ }^{1}$ Department of Marketing and Logistics Management, National Penghu University, Penghu, Taiwan, China; ${ }^{2}$ Graduate Institute of \\ Marine Creative Industry, National Penghu University, Penghu, Taiwan, China. \\ Email: csc@npu.edu.tw
}

Received March 30 ${ }^{\text {th }}, 2010$; revised April 30 $0^{\text {th }}, 2010$; accepted May 31 $1^{\text {st }}, 2010$.

\begin{abstract}
The purpose of this study is to understand the relationship among marine tourism employee's personality traits, work motivation and innovative behavior. In order to meet this purpose, the study conducts questionnaire survey. Questionnaire sample of 250 has been handed out and 215 valid samples have been collected. The results show that employees with higher intrinsic work motivation are more likely to generate innovative behavior. The compensation in extrinsic work motivation has a positive effect on employee's innovative behavior. Intrinsic work motivation has mediated effect between personality traits and innovative behavior. Extrinsic work motivation has partial mediated effect between personality traits and innovative behavior.
\end{abstract}

Keywords: Marine Tourism Industry, Personality Traits, Work Motivation, Innovative Behavior

\section{Introduction}

Tourism has become one of the most important industries in the world, it was also called "industry without chimneys", and its economic influences are vital for many countries [1]. Based on 2007 world tourism analysis reports, global tourist numbers reached 898 million in 2007 and created US 7.06 trillion economic outputs, the income will account for $10.4 \%$ of the world's GDP and 231 million people will be employed by the industry [2]. The tourism industry increasingly plays an important role in the global economic development. Taiwan's global travel and tourism competitiveness was ranked 30th in the world, the total demand of tourism traveling industry reached US 3.789 billion, it contributed $4.51 \%$ to Taiwan's GDP and created five hundreds and thirty thousands job opportunities [2,3]. For many islands and countries situated near sea, marine tourism is an important part in tourism industry, and it will compensate for Taiwan's inadequate land space for recreation by developing marine tourism.

Tourism industry is based on providing service and by contacting with customers to fully satisfy customers' needs for goods or services, since works are completed by personnel workforces, and workforces are important assets for enterprises. Personnel are originators of inno- vation, and they are the most precious resource in modern enterprise. To encourage personnel transforming their creativity into practical innovative behavior has become a popular issue in recent years $[4,5]$. The business continuity depends on its innovation of organizations; the creativity and innovation are the main innovation origin of the enterprises. If their employees can effectively execute their innovative behavior, it will help their enterprises stand out of complicated business environment [6]. Earlier researches of innovative behavior were focused on the discussion of personal creativity. However, personal creativity is just one part of personal innovative behavior, and innovative behavior starts from the creativity of personnel, creativity helps the execution of innovative behavior [7]. Creativity and the personality traits of creator are mutually correlated, the relationship between personality traits and creativity was important research topic in the past [8]. The personality traits can considerably interpret the happening cause and forecasting on innovative behavior [9]. However, it is not fully understood on the relationship between personality traits and innovative behavior in the past, this contributes to the research motive of this study. Work motivation is the composing element of creativity, they are correlated to some extent, and work motivation can be divided into 
intrinsic motivation and extrinsic motivation. Intrinsic motivation positively influences creativity, extrinsic motivation is beneficial to the development of creativity in certain scenarios $[10,11]$. The creativity and innovative behavior of personnel are the main resources of enterprise innovation, however, the innovative behavior of personnel will not generate automatically, and managers should give their employees appropriate work motivations and further confirm the influence on their innovative behavior. It is hoped to offer references for management in the industry. This study is to discuss what will affect innovative behavior by personality traits and work motivation; it is the second motivations of this study.

This research uses the employees of marine tourism industry in Penghu as the study target, and it is hoped to understand how personality traits and work motivation affect the innovative behavior.

\section{Literature Review and Hypothesis}

For many islands and countries situated near the sea, marine tourism is always an important contributing component for tourism industry, the growth of marine tourism industry is faster than other tourism industries [12]. The related business include vocation resort, hotels, ferries, beaches, seabed tourism ship, yacht business, promenade sightseeing, swimming and diving equipment, fishing equipments, equipment leasing, ferry and cruise business, souvenir sell [12]. This research assumes that marine tourism industry should include all the recreational activities subjected by marine environment such as traffic, dinning, hotels, traveling, recreation, entertainment and other related industries, it includes those recreational activities that involve travel away from one's place of residence.

\subsection{The Relationship between Personality Traits and Innovative Behavior}

Among the theory of personality traits, Costa, McCrae\& Busch congregate many views of personality traits, their proposed personality traits are widely accepted [13]. The agreeableness, conscientiousness, extraversion and neuroticism of personality traits can considerably interpret the happening cause and forecasting on personal behavior $[14,15]$. However some researchers indicated that if there are too many extrovert personnel in a team, it will have an adverse effect. While each does things in his way, it will be adverse to the achievements of a team [16].

Based on above literatures, this study proposes the hypothesis:

H1: The personality traits of the marine tourism personnel have a significant influence on their innovative behavior.

\subsection{The Relationship between Personality Traits and Work Motivation}

Amabile et al. (1994) divided personality traits into sixteen types according to Myers-Briggs Type Inventory (MBTI) [17], it is found that personnel with extrinsic motivation inclination is positively related with the extraversion in personality trait; however, personnel with intrinsic motivation inclination is not positively related with the introversion in personality traits. According to above literature, personality traits and work motivation have mutual influence, and personnel with different personality traits will have disparate work motivations.

Hence, this research proposes the following hypotheses:

$\mathrm{H} 2$ : The personality traits of the marine tourism personnel have a significant influence on intrinsic work motivation.

H3: The personality traits of the marine tourism personnel have significant influences on their extrinsic work motivation.

\subsection{The Relationship between Work Motivation and Innovative Behavior}

Work motivation produces influences on different stages of innovative behavior; intrinsic motivation has significant positive interpretation and forecast on personal creativity and organizational innovation [18]. Most researches indicated that extrinsic motivation like gaining recognition and monetary reward will produce negative influence and extrinsic motivation factors like lack of liberty, unable to get support from supervisors and afraid of being evaluated, these factors will bring negative forecast to creativity [17]. However, extrinsic motivation might not produce negative influence on personnel who carries on creative activity [18]. Some researchers assume that extrinsic motivation produces negative influence on creativity; in the other hand, the predictability of extrinsic motivation on innovative behavior could be a positive or a negative influence.

Based on above literatures, this study proposes the hypothesis:

H4: The intrinsic work motivation of the marine tourism personnel has significant influences on their innovative behavior.

H5: The extrinsic work motivation of the marine tourism personnel has significant influences on their innovative behavior.

\subsection{The Relationship among Personality Traits, Work Motivation and Innovative Behavior}

Recent studies indicated that personality traits have a positive influence on innovative behavior $[9,14]$ however some researchers proposed different opinions [16]. Intrinsic motivation is positively related to innovative behav- 
ior $[5,18]$, the factors of extrinsic motivation also have predictability on creativity $[17,18]$. Hence, this study tries to use the widely accepted "Big Five" personality traits and work motivation as research topic, and then discusses what kind of work motivation will be generate by some specific personality traits, and managers should give their employees appropriate work motivations according to different personality traits, and further confirm the influence on their innovative behavior.

Hence, this research proposes the following hypotheses:

H6: The intrinsic work motivation of the marine tourism personnel has significant mediating effect between their personality traits and innovative behavior.

H7: The extrinsic work motivation of the marine tourism personnel has significant mediating effect between their personality traits and innovative behavior.

\section{Methodology}

\subsection{Research Framework}

To combine with the literature review in previous chapter, this study uses the integrated model of the personality traits, work motivation and innovative behavior to discuss how personality traits of personnel of marine tourism affect their innovative behavior (H1), the interactions among the personality traits, extrinsic and intrinsic work motivations (H2, H3), how intrinsic and extrinsic work motivations affect innovative behavior $(\mathrm{H} 4, \mathrm{H} 5)$, whether or not intrinsic and extrinsic work motivations have significant mediating effect on personality traits and innovative behavior (H6, H7). The research framework of this study is shown as Figure 1.

\subsection{Procedure}

The questionnaire method was conducted to carry out the survey. The content of the questionnaire consisted of four parts: personality traits, work motivation, innovative behavior and basic data. Respective items were developed based on the evaluation index proposed by scholars' inre- lated area. These survey items were revised deliberately and then the questionnaires distributing procedure was conducted. The distributed spots were on the marine tourism commercial resort in Penghu, Taiwan. There were 250 questionnaires distributed totally, and we subtracted the invalid questionnaires which were blank and incomplete answered, there were 215 valid samples back, the valid response rate was $86 \%$.

\subsection{Measurement Tool}

This study refers the study of McCrace \& Costa (1992) [16], the five personality traits (Big Five personality) were adopted as the evaluation index basis. The Cronbach's $\alpha$ value of personality traits was 0.72 . In the work motivation, this study adopted Amabile et al. (1994) [17] \& Fang's (2002) [19] Work Preference Inventory (WPI) scale, the Cronbach's $\alpha$ value for the both scales were 0.81 and 0.74 . For the innovative behavior questionnaire, this study used the innovative behavior scale developed by Scott $\&$ Bruce (1994) [20]. The Cronbach's $\alpha$ value was 0.88 , the result indicated that the questionnaire reliability was acceptable.

\section{Results}

\subsection{The Relationship between Personality Traits and Innovative Behavior}

As the Table 1 shows, the three factors: agreeableness, extraversion and openness to experience of personality traits could explain $9 \%$ of the idea generation factor in innovative behavior $(\mathrm{F}=4.11, \mathrm{p}<0.001)$; the three factors; agreeableness, extraversion and openness to experience of personality traits could explain $10 \%$ of the idea promotion factor in innovative behavior $(\mathrm{F}=4.59, \mathrm{p}$ $<0.001$ ); the three factors: agreeableness, extraversion and openness to experience of personality traits could explain $10 \%$ of the idea implementation factor in innovative behavior $(\mathrm{F}=4.83, \mathrm{p}<0.001)$; they all reached the significant level, $\mathrm{H} 1$ was supported.

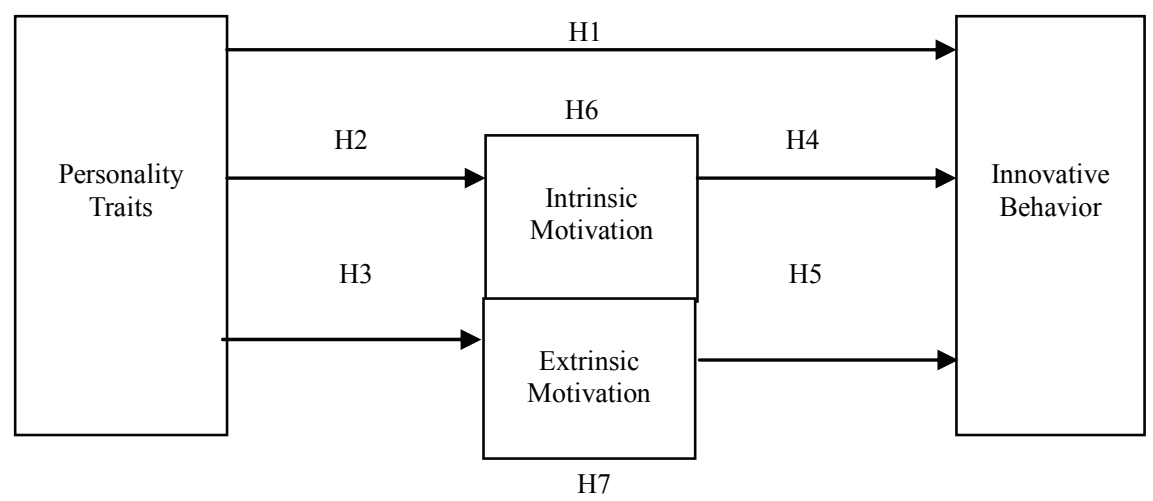

Figure 1. The research framework 


\subsection{The Relationship between Personality Traits and Work Motivation}

After regression analysis, shown in Table 1, the agreeableness and extraversion factors of personality traits could explain $9 \%$ of the enjoyment factor in work motivation $(\mathrm{F}=4.21, \mathrm{p}<0.001)$; the three factors: agreeableness, extraversion and openness to experience of personality traits could totally explain $19 \%$ of the challenge factor in work motivation $(\mathrm{F}=10.06, \mathrm{p}<0.001)$; they all reached the significant level, H2 was supported. The three factors: conscientiousness, neuroticism and openness to experience of personality traits could totally explain $10 \%$ of the outward factor in work motivation $(\mathrm{F}=4.64, \mathrm{p}<$ $0.001)$; the four factors: agreeableness, extraversion, neuroticism and openness to experience of personality traits could totally explain $10 \%$ of the outward factor in work motivation $(\mathrm{F}=4.54, \mathrm{p}<0.001)$; they all reached the significant level.

\subsection{The Relationship between Work Motivation and Innovative Behavior}

As the regression analysis in Table 2 shows, the enjoyment and challenge factors of intrinsic work motivation could explain $24 \%$ of the idea generation factor in innovative behavior $(\mathrm{F}=33.96, \mathrm{p}<0.001)$; the enjoyment and challenge factors of intrinsic work motivation could explain $24 \%$ of the idea promotion factor in innovative $(\mathrm{F}=33.10, \mathrm{p}<0.001)$; the enjoyment and challenge factors of intrinsic work motivation could explain $26 \%$ of the idea implementation factor in innovative behavior $(\mathrm{F}$ $=37.55, \mathrm{p}<0.001)$; they all reached the significant level. Hence, H4 was supported.

As the regression analysis in Table 3 shows, the compensation factor in extrinsic work motivation could explain $10 \%$ of the idea generation factor in innovative behavior $(\mathrm{F}=12.14, \mathrm{p}<0.00)$; the compensation factor in extrinsic work motivation could explain $13 \%$ of the idea promotion factor in innovative behavior $(\mathrm{F}=15.30$, $\mathrm{p}<0.001)$; the compensation factor in extrinsic work motivation could explain $14 \%$ of the idea implementation factor in innovative behavior $(\mathrm{F}=17.08, \mathrm{p}<0.001)$; they all reached the significant level, H5 was supported.

\subsection{The Relationship among Personality Traits, Work Motivation and Innovative Behavior}

As the multiple regression analysis in Table 4 shows, the three factors: agreeableness, extraversion and openness to experience of personality traits were significantly correlated with the idea generation factor in innovative behavior. The enjoyment and challenge factors of work motivation were significantly correlated with the idea generation factor in innovative behavior work motivation. However, if two factors of intrinsic work motivation were added into the predictive variables, the correlation among dependent variable and three personality traits factors became insignificant, the $\beta$-value would be smaller than the initial $\beta$-value, though the enjoyment and challenge factors of intrinsic work motivation were still significantly correlated with idea generation.

As Table 5 shows, the three factors-agreeableness, extraversion and openness to experience of personality traits were significantly correlated with the idea promotion factor in innovative behavior. The enjoyment and challenge factors of work motivation were significantly correlated with the idea promotion factor in innovative behavior. However, if two factors of intrinsic work motivetion were added into the predictive variables, the correlation among dependent variable and three personality traits factors became insignificant, the $\beta$-value would be smaller than the initial $\beta$-value, though the enjoyment and challenge factors of intrinsic work motivation were still significantly correlated with idea promotion.

As the multiple regression analysis in Table 6 shows, the three factors: agreeableness, extraversion and openness to experience of personality traits were significantly correlated with the idea implementation factor in innovative behavior. The enjoyment and challenge factors of work motivation were significantly correlated with the idea implementation factor in innovative behavior. However, if two factors of intrinsic work motivation were added into the predictive variables, the correlation among dependent variable and three personality traits factors became insignificant, the $\beta$-value would be smaller than the initial $\beta$-value, though the enjoyment and challenge factors of intrinsic work motivation were still signifycantly correlated with idea implementation.

Table 1. Regression analysis of personality traits and work motivation and innovative behavior

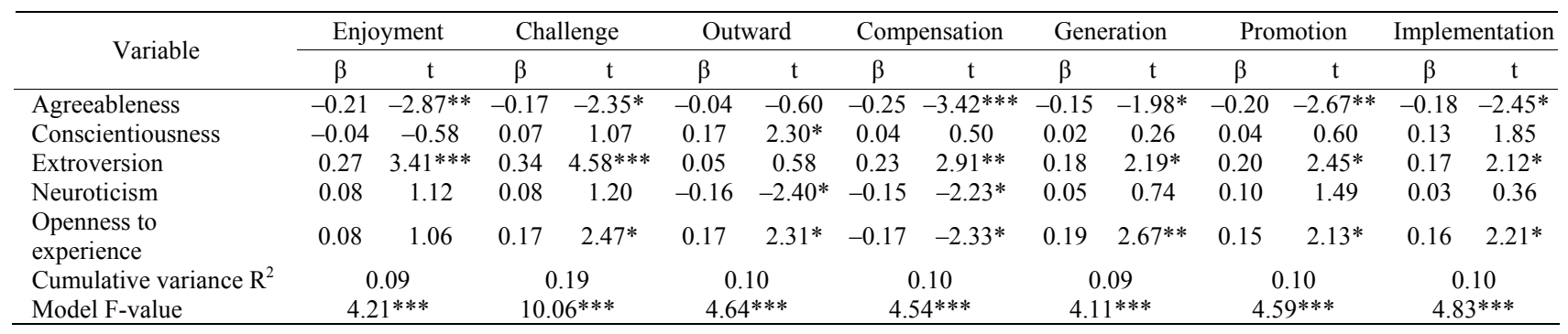

$* \mathrm{p}<0.05, * * \mathrm{p}<0.01, * * * \mathrm{p}<0.001$ 
Table 2. Regression analysis of intrinsic work motivation on innovative behavior

\begin{tabular}{|c|c|c|c|c|c|c|}
\hline \multirow{2}{*}{ Variable } & \multicolumn{2}{|c|}{ Idea generation } & \multicolumn{2}{|c|}{ Idea promotion } & \multicolumn{2}{|c|}{ Idea implementation } \\
\hline & $\beta$-value & t-value & $\beta$-value & t-value & $\beta$-value & t-value \\
\hline Enjoyment & 0.31 & $4.92 * * *$ & 0.35 & $5.52^{* * *}$ & 0.42 & $6.69^{* * *}$ \\
\hline Challenge & 0.29 & $4.51 * * *$ & 0.24 & $3.70^{* * *}$ & 0.18 & $2.86 * *$ \\
\hline Cumulative variance $\mathrm{R}^{2}$ & \multicolumn{2}{|c|}{0.24} & \multicolumn{2}{|c|}{0.24} & \multicolumn{2}{|c|}{0.26} \\
\hline Model F-value & \multicolumn{2}{|c|}{$33.96 * * *$} & \multicolumn{2}{|c|}{$33.10 * * *$} & \multicolumn{2}{|c|}{$37.55^{* * *}$} \\
\hline
\end{tabular}

$* * \mathrm{p}<0.01, * * * \mathrm{p}<0.001$

Table 3. Regression analysis of extrinsic work motivation on innovative behavior

\begin{tabular}{|c|c|c|c|c|c|c|}
\hline \multirow{2}{*}{ Variable } & \multicolumn{2}{|c|}{ Idea generation } & \multicolumn{2}{|c|}{ Idea promotion } & \multicolumn{2}{|c|}{ Idea implementation } \\
\hline & $\beta$-value & t-value & $\beta$-value & t-value & $\beta$-value & t-value \\
\hline Extroversion & -0.02 & -0.27 & 0.04 & 0.56 & 0.06 & 0.95 \\
\hline Economic Reward & 0.32 & $4.90^{* * *}$ & 0.35 & $5.35^{* * *}$ & 0.36 & $5.55 * * *$ \\
\hline Cumulative variance $\mathrm{R}^{2}$ & \multicolumn{2}{|c|}{0.10} & \multicolumn{2}{|c|}{0.13} & \multicolumn{2}{|c|}{0.14} \\
\hline Model F-value & \multicolumn{2}{|c|}{$12.14 * * *$} & \multicolumn{2}{|c|}{$15.30 * * *$} & \multicolumn{2}{|c|}{$17.08 * * *$} \\
\hline
\end{tabular}

$* * * \mathrm{p}<0.001$

Table 4. Hierarchical regression analysis of personality traits and intrinsic work motivation on idea generation

\begin{tabular}{|c|c|c|c|c|c|c|c|c|c|}
\hline \multirow{2}{*}{ Variable } & \multicolumn{3}{|c|}{ Analysis 1} & \multicolumn{3}{|c|}{ Analysis 2} & \multicolumn{3}{|c|}{ Analysis 3} \\
\hline & $\beta$ & $\mathrm{t}$ & VIF & $\beta$ & $\mathrm{t}$ & VIF & $\beta$ & $\mathrm{t}$ & VIF \\
\hline Agreeableness & -0.15 & $-1.98 *$ & 1.28 & - & - & - & -0.04 & -0.59 & 1.35 \\
\hline Conscientiousness & 0.02 & 0.26 & 1.22 & - & - & - & 0.01 & 0.21 & 1.24 \\
\hline Extroversion & 0.18 & $2.19^{*}$ & 1.47 & - & - & - & 0.01 & 0.08 & 1.65 \\
\hline Neuroticism & 0.05 & 0.74 & 1.09 & - & - & - & 0.01 & 0.13 & 1.10 \\
\hline Openness & 0.19 & $2.67 * *$ & 1.20 & - & - & - & 0.13 & 1.92 & 1.23 \\
\hline Enjoyment & - & - & - & 0.31 & $4.92 * * *$ & 1.14 & 0.30 & $4.67 * * *$ & 1.19 \\
\hline Challenge & - & - & - & 0.29 & $4.51 * * *$ & 1.14 & 0.25 & $3.62 * * *$ & 1.34 \\
\hline Cumulative variance $\mathrm{R}^{2}$ & \multicolumn{3}{|c|}{0.09} & \multicolumn{3}{|c|}{0.24} & \multicolumn{3}{|c|}{0.26} \\
\hline Model F-value & \multicolumn{3}{|c|}{$4.11 * * *$} & \multicolumn{3}{|c|}{$33.96 * * *$} & \multicolumn{3}{|c|}{$10.33 * * *$} \\
\hline
\end{tabular}

${ }^{*} \mathrm{p}<0.05,{ }^{* * \mathrm{p}}<0.01,{ }^{* * *} \mathrm{p}<0.001$

Table 5. Hierarchical regression analysis of personality traits and intrinsic work motivation on idea promotion

\begin{tabular}{|c|c|c|c|c|c|c|c|c|c|}
\hline \multirow{2}{*}{ Variable } & \multicolumn{3}{|c|}{ Analysis 1} & \multicolumn{3}{|c|}{ Analysis 2} & \multicolumn{3}{|c|}{ Analysis 3} \\
\hline & $\beta$ & $\mathrm{t}$ & VIF & $\beta$ & $\mathrm{t}$ & VIF & $\beta$ & $\mathrm{t}$ & VIF \\
\hline Agreeableness & -0.20 & $-2.67 * *$ & 1.28 & - & - & - & -0.10 & -1.38 & 1.35 \\
\hline Conscientiousness & 0.04 & 0.60 & 1.22 & - & - & - & 0.04 & 0.66 & 1.24 \\
\hline Extraversion & 0.20 & $2.45^{*}$ & 1.47 & - & - & - & 0.04 & 0.50 & 1.65 \\
\hline Neuroticism & 0.10 & 1.49 & 1.09 & - & - & - & 0.06 & 0.98 & 1.10 \\
\hline Openness to experience & 0.15 & $2.13 *$ & 1.20 & - & - & - & 0.10 & 1.44 & 1.23 \\
\hline Enjoyment & - & - & - & 0.35 & $5.52 * * *$ & 1.14 & 0.33 & $5.13 * * *$ & 1.19 \\
\hline Challenge & - & - & - & 0.24 & $3.70 * * *$ & 1.14 & 0.19 & $2.72 * *$ & 1.34 \\
\hline Cumulative variance $R^{2}$ & & 0.10 & & & 0.24 & & & 0.26 & \\
\hline Model F-value & & $4.59 * * *$ & & & $33.10 * * *$ & & & $10.27 * * *$ & \\
\hline
\end{tabular}

${ }^{*} \mathrm{p}<0.05,{ }^{* *} \mathrm{p}<0.01,{ }^{* * *} \mathrm{p}<0.001$ 
Based on the above results, the factors of innovative behavior were significantly correlated with partial factors of personality traits, the factors of innovative behavior were also significantly correlated with factors of intrinsic work motivation. The correlation among factors of innovative behavior and factors of personality traits became less significant with the inclusion of factors of intrinsic work motivation; the $\beta$-value would be smaller than the initial $\beta$-value. It concluded that the intrinsic work motivation was the mediating variable between personality traits and innovative behavior. Hence, H6 was supported.

As the multiple regression analysis in Table 7 shows, when two factors of extrinsic work motivation were added into the predictive variables, the correlation among dependent variable and agreeableness and extraversion factors in personality traits became insignificant, the $\beta$ value would be smaller than the initial $\beta$-value, though the compensation factor of extrinsic work motivation was significantly correlated with idea generation.

When two factors of extrinsic work motivation were added into the predictive variables, the correlation among dependent variable and agreeableness and extraversion factors in personality traits became insignificant, the $\beta$ value would be smaller than the initial $\beta$-value, though the outward factor of extrinsic work motivation was significantly correlated with idea promotion. It shows in Table 8.

When two factors of extrinsic work motivation were added into the predictive variables, the correlation among dependent variable and agreeableness and extraversion factors in personality traits became insignificant, the respective $\beta$-values on innovative behavior became smaller, though the compensation factor of extrinsic work motivation was significantly correlated with idea implementation. It shows in Table 9.

According to the above research results, the factors of innovative behavior are significantly correlated with factors of extrinsic work motivation. The correlation among factors of innovative behavior, factors of personality traits and factors of work motivation became less significant when factors of extrinsic work motivation were added into the predictive variables. Factors of personality traits and factors of innovative behavior were insignificant though they were initially significant correlated, the respective $\beta$-values on innovative behavior also became smaller, therefore, the extrinsic work motivation was the mediating variable between personality traits and innovative behavior. Hence, $\mathrm{H} 7$ was partial supported.

Table 6. Hierarchical regression analysis of personality traits and intrinsic work motivation on idea implementation

\begin{tabular}{|c|c|c|c|c|c|c|c|c|c|}
\hline \multirow{2}{*}{ Variable } & \multicolumn{3}{|c|}{ Analysis 1} & \multicolumn{3}{|c|}{ Analysis 2} & \multicolumn{3}{|c|}{ Analysis 3} \\
\hline & $\beta$ & $\mathrm{t}$ & VIF & $\beta$ & $\mathrm{t}$ & VIF & $\beta$ & $\mathrm{t}$ & VIF \\
\hline Agreeableness & -0.18 & $-2.45^{*}$ & 1.28 & - & - & - & -0.07 & -1.06 & 1.35 \\
\hline Conscientiousness & 0.13 & 1.85 & 1.22 & - & - & - & 0.14 & $2.21 *$ & 1.24 \\
\hline Extraversion & 0.17 & $2.12 *$ & 1.47 & - & - & - & 0.01 & 0.15 & 1.65 \\
\hline Neuroticism & 0.03 & 0.36 & 1.09 & - & - & - & 0.02 & -0.28 & 1.10 \\
\hline Openness & 0.16 & $2.21 *$ & 1.20 & - & - & - & 0.11 & 1.63 & 1.23 \\
\hline Enjoyment & - & - & - & 0.42 & $6.69 * * *$ & 1.14 & 0.42 & $6.59 * * *$ & 1.19 \\
\hline Challenge & - & - & - & 0.18 & $2.86 * *$ & 1.14 & 0.12 & 1.84 & 1.34 \\
\hline Cumulative variance $\mathrm{R}^{2}$ & \multicolumn{3}{|c|}{0.10} & \multicolumn{3}{|c|}{0.26} & \multicolumn{3}{|c|}{0.30} \\
\hline Model F-value & \multicolumn{3}{|c|}{$4.83 * * *$} & \multicolumn{3}{|c|}{$37.55 * * *$} & \multicolumn{3}{|c|}{$12.55 * * *$} \\
\hline
\end{tabular}

$* \mathrm{p}<0.05, * * \mathrm{p}<0.01, * * * \mathrm{p}<0.001$

Table 7. Hierarchical regression analysis of personality traits and extrinsic work motivation on idea generation

\begin{tabular}{|c|c|c|c|c|c|c|c|c|c|}
\hline \multirow{2}{*}{ Variable } & \multicolumn{3}{|c|}{ Analysis 1} & \multicolumn{3}{|c|}{ Analysis 2} & \multicolumn{3}{|c|}{ Analysis 3} \\
\hline & $\beta$ & $\mathrm{t}$ & VIF & $\beta$ & $\mathrm{t}$ & VIF & $\beta$ & $\mathrm{t}$ & VIF \\
\hline Agreeableness & -0.15 & $-1.98^{*}$ & 1.28 & - & - & - & -0.06 & -0.83 & 1.35 \\
\hline Conscientiousness & 0.02 & 0.26 & 1.22 & - & - & - & 0.02 & 0.29 & 1.26 \\
\hline Extraversion & 0.18 & $2.19^{*}$ & 1.47 & - & - & - & 0.10 & 1.25 & 1.53 \\
\hline Neuroticism & 0.05 & 0.74 & 1.09 & - & - & - & 0.09 & 1.40 & 1.13 \\
\hline Openness to experience & 0.19 & $2.67 * *$ & 1.20 & - & - & - & 0.27 & $3.82 * * *$ & 1.27 \\
\hline Outward & - & - & - & -0.02 & -0.27 & -0.02 & -0.08 & -1.26 & 1.14 \\
\hline Compensation & _ & - & _- & 0.32 & $4.90 * * *$ & 0.32 & 0.36 & $5.47 * * *$ & 1.14 \\
\hline Cumulative variance $\mathrm{R}^{2}$ & & 0.09 & & & 0.10 & & & 0.21 & \\
\hline Model F-value & & $4.11 * * *$ & & & $12.14 * * *$ & & & $7.62 * * *$ & \\
\hline
\end{tabular}

$*_{\mathrm{p}}<0.05, *{ }_{\mathrm{p}}<0.01, * * \mathrm{p}<0.001$ 
Table 8. Hierarchical regression analysis of personality traits and extrinsic work motivation on idea promotion

\begin{tabular}{|c|c|c|c|c|c|c|c|c|c|}
\hline \multirow{2}{*}{ Variable } & \multicolumn{3}{|c|}{ Analysis 1} & \multicolumn{3}{|c|}{ Analysis 2} & \multicolumn{3}{|c|}{ Analysis 3} \\
\hline & $\beta$ & $\mathrm{t}$ & VIF & $\beta$ & $\mathrm{t}$ & VIF & $\beta$ & $\mathrm{t}$ & VIF \\
\hline Agreeableness & -0.20 & $-2.67 * *$ & 1.28 & - & - & - & -0.10 & -1.44 & 1.35 \\
\hline Conscientiousness & 0.04 & 0.60 & 1.22 & - & - & - & 0.03 & 0.46 & 1.26 \\
\hline Extraversion & 0.20 & $2.45^{*}$ & 1.47 & - & - & - & 0.11 & 1.43 & 1.53 \\
\hline Neuroticism & 0.10 & 1.49 & 1.09 & - & - & - & 0.16 & $2.43^{*}$ & 1.13 \\
\hline Openness to experience & 0.15 & $2.13 *$ & 1.20 & - & - & - & 0.22 & $3.16^{* *}$ & 1.27 \\
\hline Outward & - & - & - & 0.04 & 0.56 & 0.04 & -0.01 & 0.16 & 1.14 \\
\hline Compensation & - & - & - & 0.35 & $5.35 * * *$ & 0.35 & 0.38 & $5.80 * * *$ & 1.14 \\
\hline $\begin{array}{l}\text { Cumulative variance } \mathrm{R}^{2} \\
\text { Model F-value }\end{array}$ & & $\begin{array}{c}0.10 \\
4.59^{* * *}\end{array}$ & & & $\begin{array}{c}0.13 \\
15.30^{* * *}\end{array}$ & & & & \\
\hline
\end{tabular}

${ }^{*} \mathrm{p}<0.05, * \mathrm{p}<0.01, * * \mathrm{p}<0.001$

Table 9. Hierarchical regression analysis of personality traits and extrinsic work motivation on idea implementation

\begin{tabular}{|c|c|c|c|c|c|c|c|c|c|}
\hline \multirow{2}{*}{ Variable } & \multicolumn{3}{|c|}{ Analysis 1} & \multicolumn{3}{|c|}{ Analysis 2} & \multicolumn{3}{|c|}{ Analysis 3} \\
\hline & $\beta$ & $\mathrm{t}$ & VIF & $\beta$ & $\mathrm{t}$ & VIF & $\beta$ & $\mathrm{t}$ & VIF \\
\hline Agreeableness & -0.18 & $-2.45^{*}$ & 1.28 & - & - & - & -0.08 & -1.18 & 1.35 \\
\hline Conscientiousness & 0.13 & 1.85 & 1.22 & - & - & - & 0.12 & 1.80 & 1.26 \\
\hline Extraversion & 0.17 & $2.12 *$ & 1.47 & - & - & - & 0.08 & 1.04 & 1.53 \\
\hline Neuroticism & 0.03 & 0.36 & 1.09 & - & - & - & 0.08 & 1.27 & 1.13 \\
\hline Openness to experience & 0.16 & $2.21 *$ & 1.20 & - & - & - & 0.23 & $3.31 * * *$ & 1.27 \\
\hline Outward & - & - & - & 0.06 & 0.95 & 0.06 & -0.02 & -0.23 & 1.14 \\
\hline Compensation & - & - & - & 0.36 & $5.55 * * *$ & 0.36 & 0.39 & $6.05 * * *$ & 1.14 \\
\hline $\begin{array}{l}\text { Cumulative variance } \mathrm{R}^{2} \\
\text { Model F-value }\end{array}$ & & $\begin{array}{c}0.10 \\
4.83 * * *\end{array}$ & & & $\begin{array}{c}0.14 \\
17.08 * * *\end{array}$ & & & $\begin{array}{r}0 \\
9.3\end{array}$ & \\
\hline
\end{tabular}

$* \mathrm{p}<0.05, * * \mathrm{p}<0.01, * * \mathrm{p}<0.001$

\section{Conclusions \& Discussion}

The hypotheses of this research are all established. It means that employees with higher intrinsic work motivation are more likely to generate innovative behavior. The compensation in extrinsic work motivation has a positive effect to person's innovative behavior. Intrinsic work motivation has mediated effect between personality traits and innovative behavior. Extrinsic work motivation has partial mediated effect between personality traits and innovative behavior.

The findings provide several implications, first of all, if personnel have more enjoyment and challenge in their intrinsic motivation, they will exhibit more innovative behavior, therefore, the marine tourism industry should reinforce the delight and challenge in the content of the work. Personnel often chase delightful or suitable works to fulfill self-actualized. However, most works are lack of delight and challenge, and most employers have the idea that personnel work only for payroll; the employers often overlook the delightful working environment brought by work's delight and the sense of achievement brought by challenging work. Secondly, the compensation of extrinsic motivation is the most positively influential factor for personnel's innovative behavior, therefore, the marine tourism industry should implement a fair incentive mechanism, and it will produce irresistible attractiveness for personnel who are attached to fair incentive. In addition, the intrinsic work motivation of the marine tourism personnel will have significant mediating effect between their personality traits and innovative behavior. Therefore, the marine tourism industry should provide personnel with appropriate intrinsic work motivation according to their personal traits, it will make personnel acquire job satisfaction and the intrinsic work motivation provision will promote the development of innovative behavior. Finally, the compensation factor in extrinsic work motivation will have partial mediating effect between their personality traits and innovative behavior. Therefore, the marine tourism industry should provide personnel with appropriate extrinsic work motivation according to their personal traits, if the personnel are attached to material life then the employer should give them tangible reward, i.e. money; if the personnel are 
attached to spiritual life then they might want an endowment of power from the employer, and the appropriate reward will promote the development of innovative behavior.

Future research can extend the present study in several directions. One direction would be to replicate the same questionnaire in different area and compares with this study. For this study uses the five big personality traits as the categorization standard for personality traits, future researches could be measured with other factors in personality traits. In addition, this research uses intrinsic work motivation and extrinsic work motivation as the categorization of work motivation, the results could not fully support all the hypotheses proposed by this research, future researchers can measure with other factors to improve the predictabilities.

\section{REFERENCES}

[1] H. Fayed and J. Fletcher, "Globalization of Economic Activity: Issues for Tourism," Tourism Economics, Vol. 8, No. 2, 2002, pp. 207-230.

[2] World Travel and Tourism Council (WTTC), "The 2007 Travel and Tourism Economic Research,” 2007。 http:// www.wttc.org/bin/pdf/original_pdf_file/world.pdf

[3] World Economic Forum (WEF), "Travel and Tourism Competitiveness Report," 2007. http://www.weforum. org/pdf/tourism/Part1.pdf

[4] T. M. Amabile and R. Conti, "Changes in The Work Environment for Creativity during Downsizing," Academy of Management Journal, Vol. 42, No. 6, 1999, pp. 630640.

[5] T. M. Amabile, R. Conti, H. Coon, J. Lazenby and M. Herron, "Assessing the Work Environment for Creativity," Academy of Management Journal, Vol. 39, No. 5, 1996, pp. 1154-1184.

[6] T. M. Amabile, "A Model of Creativity and Innovation in Organizations," In: B. M. Staw and L. L. Cumming, Eds., Research in Organizational Behavior, JAI Press, Greenwich, Vol. 10, No. 2, 1998, pp. 123-167.

[7] R. F. Kleysen and C. T. Street, "Toward a Multi-DimenSional Measure of Individual Innovative Behavior," Journal of Intellectual Capital, Vol. 2, No. 3, 2001, pp. 284296.

[8] E. C. Selby, E. J. Shaw and J. C. Houtz, "The Creative
Personality," The Gifted Child Quarterly, Vol. 49, No. 4, 2005, pp. 300-316.

[9] T. A. Judge, J. E. Bono, R. Ilies and M. W. Gerhardt, "Personality and Leadership: A Qualitative and Quantitative Review," Journal of Applied Psychology, Vol. 87, No. 4, 2002, pp. 765-780.

[10] T. M. Amabile, "The Social Psychology of Creativity," Springer-Verlag, New York, 1983.

[11] M. L. Ambrose and C. T. Kulik, "Old Friends, New Faces: Motivation Research in the 1990s," Journal of Management, Vol. 25, No. 3, 1999, pp. 231-292.

[12] C. O. Tsai, "The Research on Marine Tourism Recreation Development, Standard and Management Infrastructure," Taiwan National Science Council, 2000.

[13] P. T. Jr. Costa, R. R. McCrae and C. M. Busch, "Evaluating Comprehensiveness in Personality Systems: The California Q-Set and the Five-Factor Model," Journal of Personality, Vol. 54, No. 2, 1986, pp. 430-446.

[14] M. R. Barrick, G. L. Stewart, M. J. Neubert and M. K. Mount, "Relating Member Ability and Personality to Work-Team Processes and Team Effectiveness," Journal of Applied Psychology, Vol. 83, No. 3, 1998, pp. 377-391.

[15] T. A. Judge, J. E. Bono, R. Ilies and M. W. Gerhardt, "Personality and Leadership: A Qualitative and Quantitative Review," Journal of Applied Psychology, Vol. 87, No. 4, 2002, pp. 765-780.

[16] R. R McCrae and P. T. Jr. Costa, "An Introduction of the Five-Factor Model and its Applications," Journal of Personality, Vol. 60, No. 2, 1992, pp. 175-215.

[17] T. M. Amabile, K. G. Hill, B. A. Hennessey and E. M. Tighe, "The Work Preference Inventory: Assessing Intrinsic and Extrinsic Motivational Orientations," Journal of Personality and Social Psychology, Vol. 66, No. 5, 1994, pp. 950-967.

[18] T. M. Amabile, "Creativity in Context," West View Press, Boulder, 1996.

[19] M Fang, “A Study of the Organizational Culture's Correlation Influence on Intrinsic Work Motivation and Job Characteristics and Job Satisfaction in Taiwan SemiConductor Industry," Management Review, Vol. 21, No. 3, 2002, pp. 69-96.

[20] S. G. Scott and R. A. Bruce, "Determinants of Innovative Behavior: A Path Model of Individual Innovation in the Workplace," Academy of Management Journal, Vol. 37, No. 3, 1994, pp. 580-607. 